\title{
$\mathrm{VII} \mathrm{CINCCI}$
}

VII Colóquio internacional sobre Comércio e Cidade

Fortaleza, 03 a 07 de Novembro de 2020

\section{Dinâmica socioespacial da feira livre de São Bento na cidade de Cascavel/CE.}

Socio-spatial dynamics of the São Bento open market of the city of Cascavel/CE.

Dinámica socioespacial del mercado abierto de São Bento de la ciudad de Cascavel/CE.

COSTA, Regiane; Doutoranda em Geografia; Universidade Estadual do Ceará (UECE)

regiane3074@gmail.com

\section{Resumo}

Esse artigo apresenta parte da pesquisa de mestrado que focou na dinâmica espacial das feiras livres e o espaço urbano. A feira de São Bento em Cascavel/CE foi o objeto analisado a partir das modificações das formas de consumo e expansão no espaço urbano. No decorrer da pesquisa, discutiu-se os elementos que incentivam o consumo e as estratégias para esta se manter como forma comercial no tecido urbano de Cascavel. Para essa análise, seguimos leituras referentes aos conceitos, categorias tais como: cidade, espaço urbano, comércio, consumo que serviram para compreender à expansão/organização e função desse mercado periódico.

Palavra-chave: Feiras livres. Espaço urbano. Comércio.

\section{Abstract}

This article presents part of a master's research with a general focus on the spatial dynamics of open-air markets and the urban space. The main subject was the São Bento open-air market in Cascavel/CE, with a focus on the changes in the ways of consumption and the expansion in the urban space. During the research, the elements which encourage consumption and the strategies of this market to persist as a commercial shape in the urban fabric of Cascavel were discussed. For this analysis, we followed a literature referring to concepts and categories such as: city, urban space, commerce, consumption which served to understand the expansion/organization of this periodic Market.

Keyword: Open-air markets. Urban space. Trade.

\section{Resumen}

Este artículo presenta parte de la investigación de maestría con un enfoque general en la dinámica espacial de los mercados abiertos y el espacio urbano. La feria de São Bento en Cascavel/CE fue el objeto analizado a partir de los cambios en las formas de consumo y expansión en el espacio urbano. Durante la investigación, se 


\section{$\mathrm{VII} \mathrm{CINCCI}$}

VII Colóquio internacional sobre Comércio e Cidade

Fortaleza, 03 a 07 de Novembro de 2020

discutieron los elementos que fomentan el consumo y las estrategias para que se mantenga como forma comercial en la coyuntura urbana de Cascavel. Para este análisis, llevamos a cabo lecturas que se refieren a los conceptos, categorías tales como: ciudad, espacio urbano, comercio, consumo que sirvieron para comprender la expansión / organización de este mercado periódico

Palabra clave: Ferias gratuitas. Espacio urbano. Comercio. 


\section{Introdução}

Os estudos sobre o desenvolvimento das feiras livres desde sua origem passam por variáveis de análises associadas à dinâmica das cidades. Desde a Antiguidade elas se tornaram um elemento da cidade que favoreceu a troca e disponibilizaram à população vários tipos de mercadorias essenciais à vida. Atualmente, elas continuam agregando essas mesmas funções, pois respondem às novas estratégias de organização do comércio com diferentes produtos.

Ao observar a marcha histórica desses mercados periódicos, deparamos com o respaldo das feiras na Idade Média, o que levou Braudel (1998) a defini-las como uma das formas direta e transparente de troca em todos os continentes. Por funcionarem em espaços abertos, elas ainda se contrapõem com outros tipos de forma comercial que se reproduzem nos espaços fechados, voltados para dentro e ignorando a cidade pública com seus ambientes movimentados e animados (SALGUEIRO, 2009. p.10). No contexto da cidade, as ruas, praças e avenidas são territórios apropriados por feirantes que expõem suas mercadorias, atraindo muitos consumidores.

As feiras se espalharam por todos os continentes. Braudel (1998) cita que na Europa existiam as grandes feiras e se constituíram caminhos para comércio permanente. Segundo Bromley (1980), nas regiões subdesenvolvidas em função do comércio interno, elas se difundiram facilmente. "Na maior parte da África, Ásia e América Latina é manipulada maior quantidade e variedade de mercadorias no comércio interno" (BROMLEY, 1980, p.220).

No território brasileiro, as feiras aparecem em todas as regiões. Em algumas delas, boa parte dos comerciantes se dedicam à comercialização de produtos perecíveis, principalmente de alimentos. Essas feições são bem mais visíveis nas cidades do Sul e do Sudeste (GODOY, 2005; JESUS, 1992). Já na região Norte, elas estão vinculadas aos aspectos geográficos da região (MEDEIRO, 2010). No Nordeste, as feiras livres ainda comercializam amplas variedades de produtos, tipos e procedências, movimentando as economias de cidades. No Nordeste, nas feiras negociam-se diversos produtos artesanais, comidas típicas, vestuários, calçados, eletrônicos, e atrai um público diversificado, dando-Ihes um sentido simbólico aos lugares.

As feiras cearenses, em especial aquelas na Região Metropolitana de Fortaleza, configuram-se como experiências de grande movimentação comercial e cultural (COSTA, 2016). O resultado é a organização de um espaço marcado pela convivência de novos e velhos modos de comercializar produtos.

Enfim, as feiras livres brasileiras materializam as especificidades regionais, consolida valores tradicionais, inserem formas e movimentos diferenciados. Por isso é relevante realizar uma leitura das feiras livres que considere a compreensão das particularidades e singularidades construídas do processo da própria da feira.

Assim, esse artigo propõe reflexões de parte estudo do mestrado ${ }^{1}$, cujo a ideia central perpassou pela abordagem da temática das feiras livres e o espaço urbano. O enfoque de análise empírica foi a feira livre São Bento em Cascavel. Tem como objetivo apresentar os elementos que contribuem na dinâmica desta feira. A pesquisa de mestrado foi realizada no Laboratório de Estudos do Território e da

\footnotetext{
${ }^{1}$ A dissertação de mestrado intitulada como "Dinâmica espacial da feira de São Bento em Cascavel/Ce".
} 
Urbanização (LETUr) do Programa de pós-graduação de Geografia (PROPGEO) da Universidade Estadual do Ceará.

O texto está organizado em três tópicos, além dessa introdução: na primeira, apresentamos as relações entre as cidades, as feiras livres e comércio. A seguir apresentamos os resultados e discussões referente a organização e expansão da feira de São Bento e por fim, apresentamos as considerações finais sobre o tema proposto.

\section{As cidades e as feiras livres: a dinâmica a partir do comércio.}

A compreensão das dinâmicas das feiras livres só faz sentido se analisadas na conjuntura da origem do comércio em consonância com as dinâmicas das cidades. Sendo o comércio uma das atividades pioneiras que a sociedade conhece, pode-se considerá-lo como elemento fundamental no desenvolvimento econômico urbano. Sejam elas grandes ou pequenas, as atividades mercantis sempre se fizeram presentes em diversas formas no espaço, para atender necessidades de consumo, gerar emprego e criar relações econômicas e sociais.

O comércio em geral, especialmente a venda no varejo, é uma das atividades econômicas presente no espaço urbano, com papel relevante nos diferentes períodos históricos de organização da sociedade. A história do comércio revela a sua relação com a cidade e seu espaço urbano, pois para Ortigoza (2010, p. 26) "[...] a história do comércio se confunde com a história das cidades". A espacialização das atividades comerciais abrange pequenas, médias e grandes cidades e em muitas áreas urbanas se constituem o setor mais importante da economia.

O comércio, em suas diversas formas e funções enquanto atividade econômica satisfaz as necessidades das pessoas, difundem inovações que, para Salgueiro e Cachinho (2009), na atividade mercantil reside um verdadeiro embrião de vida urbana e pressupõe uma interação entre os lugares. Assim, o comércio é condicionado, na sua organização e funcionamento, pelo sistema de produção, distribuição da população, mudanças dos hábitos de consumo e pela organização da cidade (SALGUERIO e CACHINHO, 2009).

Desde as feiras medievais até os modernos centros, a atividade mercantil foi e continua sendo uma das principais formas de uso da terra nas cidades. Estudos sobre a função do comércio e seu uso mostram que ele faz parte da razão de ser da cidade, pois o mesmo "[...] viabiliza a sua existência, explica a sua organização e justifica muito do movimento e animação que nela acontece" (SAGUEIRO e CACHINHO, 2009, p.9).

Por isso, estudos defendem que o espaço urbano pode ser analisado tendo o comércio como foco de pesquisa. Ortigoza (2010) ratifica que a ligação do comércio com o espaço urbano faz parte de um longo processo. Da mesma forma, Pintaudi (2005) concorda que a análise do comércio explica o espaço urbano na medida em que se consideram ambos como elementos indissociáveis.

Logo, com a ampliação da troca, o comércio adquiriu várias modalidades, destacando-se o atacadista e o varejista. Neste estudo o enfoque pautará o varejo, pois entendemos que a feira livre se enquadra nessa modalidade. Vargas (2000) argumenta que o comércio varejista possui lugar de destaque no desenvolvimento urbano, pois, interfere na geração de receita e renda na medida que efetua a distribuição dos produtos gerados pelos demais setores da economia; na geração 
de oportunidades de trabalho e abastecimento da população nas suas diversas escalas de consumo. Esses fatores se concretizam com ações da atuação agentes.

Ao considerar esses elementos descritos por Vargas (2000), o comércio varejista consiste no processo de vendas de produtos e serviços para atender necessidades pessoais do consumidor final. Neste caso, as feiras livres assumem seu papel de varejo ao fornecer a mercadoria diretamente ao consumidor.

Então, as feiras livres se constituem uma forma antiga do varejo, conhecidas pelo homem desde a Antiguidade, e se tornaram efetivas nas cidades a partir da Idade Média. Ao longo do seu desenvolvimento criaram profundas raízes de relações econômica, sociais e culturais no espaço.

\section{Resultados e discussões.}

\subsection{A cidade de Cascavel e a feira livre de São Bento.}

A leitura sobre a feira de São Bento permitiu compreender como a atividade comercial, um meio de acumulação do capital, influenciou a formação do espaço urbano, (re)construindo formas e conteúdos espaciais que dinamizam a cidade de Cascavel. Por isso, apresentaremos alguns elementos sobre o recorte espacial e objeto empírico de análise a fim de articular a discussão sobre a organização e expansão dessa forma comercial no espaço urbano.

Os aspectos vinculados à localização geográfica favoreceram algumas centralidades em Cascavel, destacamos a fixação da cidade numa área litorânea, na qual facilitou as relações comerciais. Atualmente, favorecido pelo progresso técnico, continua proporcionando a existência de fluxos mais intensos que períodos anteriores. Situado no litoral leste, a $60 \mathrm{~km}$ da capital cearense, Cascavel foi um dos últimos municípios a integrar a Região Metropolitana de Fortaleza - RMF.

Os elementos genéticos de constituição do espaço urbano de Cascavel se articulam com o surgimento da feira livre de São Bento, o que possibilita compreendê-las em um mesmo caminho metodológico. As condições que fizeram Cascavel se tornarem uma cidade favoreceram o enraizamento do comércio e da sua feira livre.

A feira de São Bento se firmou ainda no final do século XIX e continua no espaço central e comercial cascavelense. Ela funciona nas manhãs de sábado, viveu as diversas fases de transformação socioeconômica a nível local, regional e nacional. Por isso, ela ganhou novas formas e usos e se adaptou às novas necessidades de consumo da população.

Ao longo da sua existência, a feira acompanhou a expansão da área comercial. Mesmo passando por três mudanças de locais, jamais saiu do núcleo urbano, ou seja, a feira cresceu espacialmente e proporcionalmente ao desenvolvimento do comércio e dos serviços.

Ao funcionar nas artérias principais, a feira possui plena funções e gente que circula e consome, e atravessa décadas em sintonia com as outras formas e conteúdo no espaço urbano. Quanto ao conteúdo, esse mercado periódico comercializa produtos manufaturados (vestuários, calçados, eletrônicos etc.), artesanais (barro, palha e rendas), alimentícios, animais e plantas.

Assim, a feira mostra resistência devido às profundas raízes e a capacidade de diálogos com outras formas do comércio (PINTAUDI, 2009). Hoje, está 
modificada na aparência, mas mantém a solidez do seu papel de centralidade comercial, e em pleno século XXI é merecedora de todas as atenções para estudo por diversas áreas do conhecimento.

\subsection{O lugar da feira livre de São Bento no espaço urbano de Cascavel.}

Um dos objetivos do estudo do mestrado foi de compreender a organização espacial da feira de São Bento, com enfoque na expansão e o papel socioespacial que este mercado periódico desempenha, com ênfase na escala temporal do século $\mathrm{XX}$.

Consideramos que essa modalidade comercial nas grandes cidades e capitais vive embates com outras formas comerciais que fazem parte do atividades hegemônicas $^{2}$ que dominam os modernos meios de comercializar e consumir. Esses choques de interesses antagônicos justificam pelo fato delas estarem presentes e terem surgido em áreas, que no futuro foram valorizadas pelo capital com o aparecimento das novas formas do comércio e consumo, e por isso necessitou de uma reorganização do espaço (JESUS, 1992). A exemplo da realidade da capital Rio de janeiro (JESUS, 1992) e em Fortaleza, especificamente os conflitos territoriais da feira José Avelino.

Mas, nas cidades de menores portes, elas exercem certa centralidade, especialmente quando estão mais distantes das capitais (CORRÊA, 2014). Todavia, nas pequenas cidades, outras variáveis explicam a relação das feiras com o espaço urbano. Um exemplo é a feira livre de São Bento em Cascavel que no decorrer do tempo não teve grandes embates pelo território ocupado. Para Silva e Spósito (2013) as cidades menores oferecem uma gama restrita de serviços a seus moradores, o que difere no gradiente de consumo se comparado aos centros superiores.

Na conjuntura da cidade de Cascavel, a feira de São Bento se localiza nas principais vias do núcleo urbano, convivendo com outras modalidades do comércio varejista e os serviços. Ao longo dos anos, a feira sofreu alguns deslocamentos, mas nunca se distanciou da área comercial da cidade. Isso revela o quanto a feira se tornou um elemento significante para a população e economia

No final do século XIX, a feira de São Bento era uma típica feira rural nordestina muito comum na região Nordeste (Figura 1). Nela eram trocados praticamente os produtos de gêneros alimentícios (farinha, feijão, peixe e artesanato).

\footnotetext{
2 Santos (1992) apresenta que o meio técnico-científico-informacional revela o impacto da globalização no território.'É nele que se instalam as atividades hegemônicas, aquelas que têm relações mais longínquas e participam do comércio internacional, fazendo com que determinados lugares se tornem mundiais.
} 


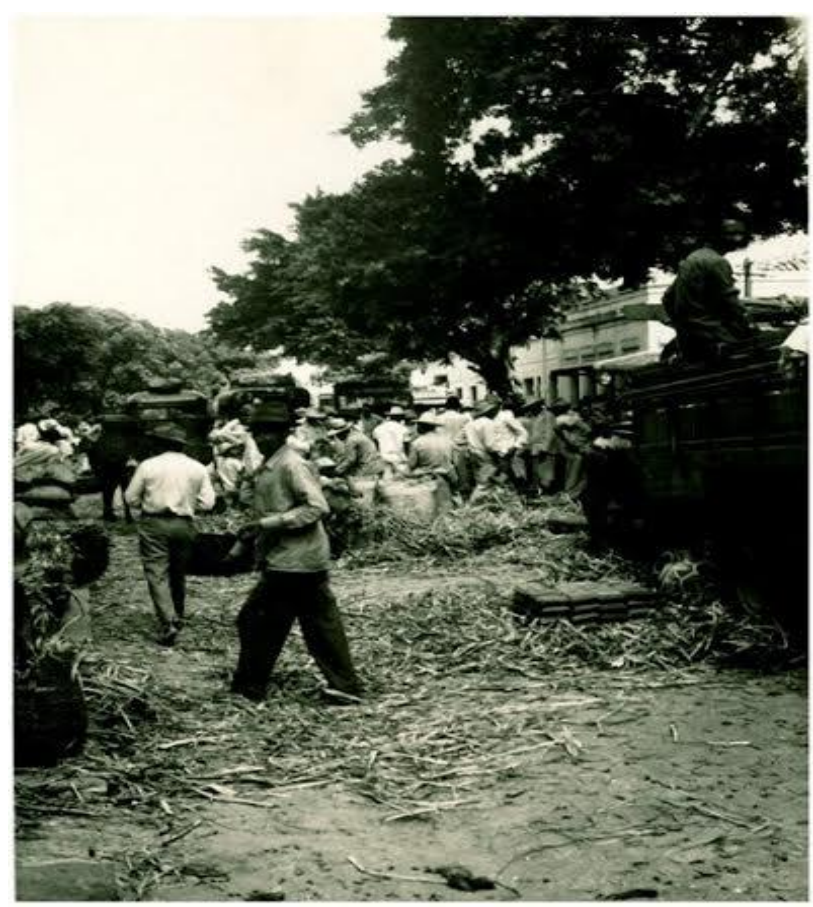

Figura 1 - Feira livre de São Bento nas primeiras décadas do século $X X$

Fonte: Kikos Barros, 2015

Segundo Shepard Forman (2009), no período colonial as feiras moviam a economia interna no Nordeste brasileiro, em muitos lugares chegavam a ser a principal forma de consumo local. Esse tipo de feira "[...] distribuía essencialmente gênero de primeira necessidade e serviços entre as pessoas do campo que dela participam como vendedores ou como compradores" (SHEPARD FORMAN, 2009, p. 114).

O resgate da organização, do conteúdo e da função da feira serve de noção de que as ações transformadoras do homem refletem diretamente na reestrutura das formas no espaço. Santos (1998) evidencia que o espaço é modificado para atender as transformações da sociedade. Isso aconteceu com Cascavel que passou por transformações socioeconômicas e que atingiu a feira de sua cidade..

Entretanto com o crescimento populacional e o surgimento de equipamentos urbanos a feira foi transferida para junto dos mercados e estabelecimentos comerciais. Nesse novo local, na primeira década do século $X X$, ela ocupava apenas a lateral externa do Mercado da Rapadura ${ }^{3}$ onde hoje funciona uma agência do banco Bradesco. É possível perceber pela Figura 2 que no início do século XX a feira teve um tímido crescimento.

\footnotetext{
${ }^{3}$ No Nordeste,a denominação barracão refere-se a um espaço amplo com cobertura para comercio de alimentos.
} 

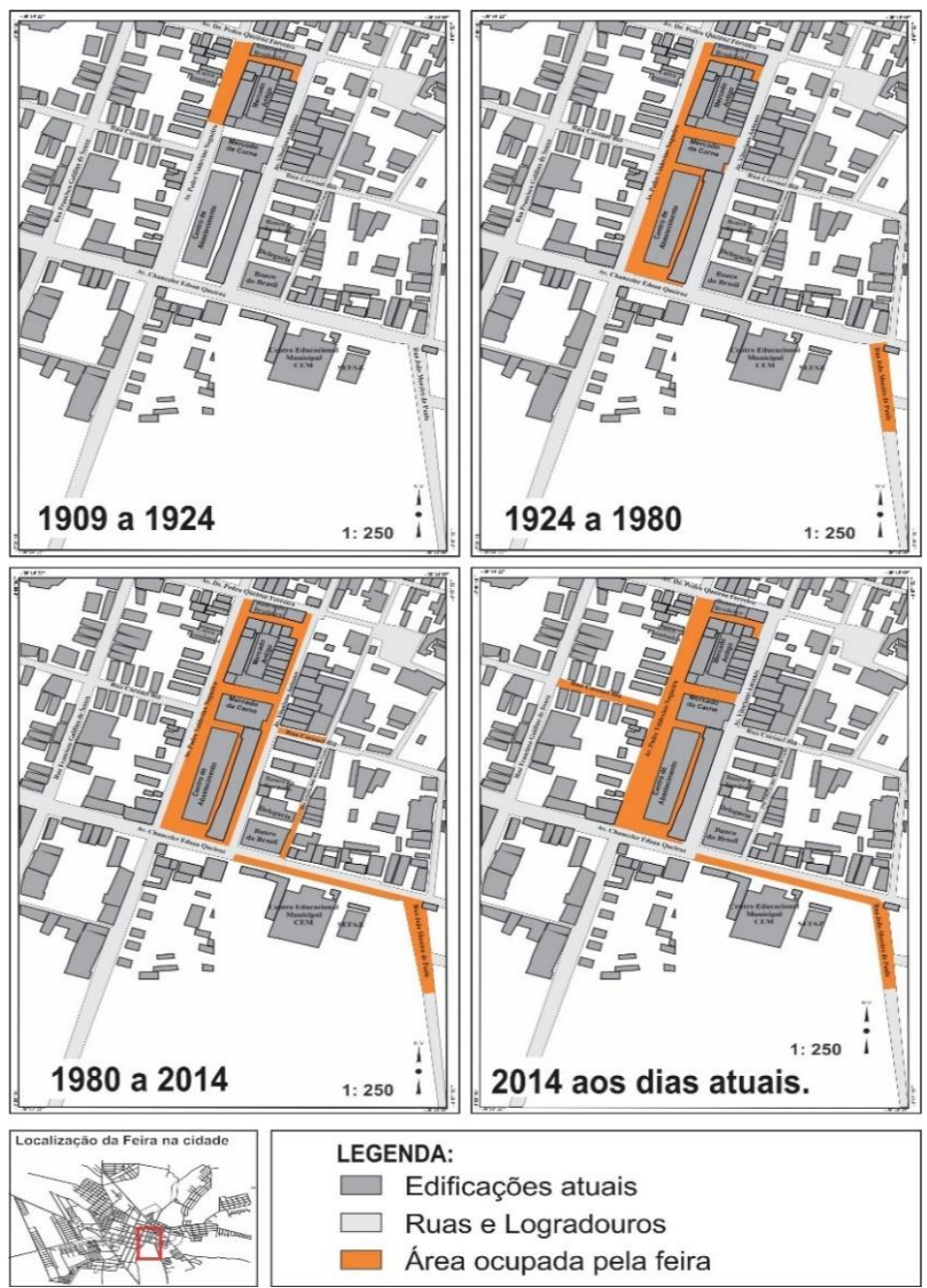

Figura 2 - Evolução espacial da feira livre de São Bento no centro urbano de Cascavel.

Base Cartográfica: Google Earth, 2015; Projeto Cartográfico: Rafael Brito; Fonte: Pesquisa em campo, 2015.

Bessa (2015) em suas pesquisas sobre a história de Cascavel, relatou que até 1924, a feira funcionava apenas em uma quadra, o que hoje corresponde a lateral do Mercado Antigo da Avenida Pe. Valdevino Nogueira. Essas vias eram largas e arborizadas preenchidas por residências e pequenos estabelecimentos comerciais.

Portanto, no decorrer do processo, o aumento de vendedores e consumidores foi intenso e a feira ocupou várias vias. Na Figura 2 é possível verificar que até a década de 1980, eles foram se apropriaram de uma das laterais da Av. Pe. Valdevino Nogueira. Não custou muito para se estender pelas Av. Vitoriano Antunes e parte da Rua Coronel Biá. Estas são as principais ruas que acolhem os equipamentos do comércio varejista e serviços, assim como a feira livre.

Para compreendermos a expansão nesta vasta área a partir das últimas décadas do século $X X$, recorremos aos dados do quantitativo de feirantes cadastrados pelos órgãos municipais nas últimas décadas. Esses dados mostraram que a expansão desse mercado periódico passou por uma maior aceleração nas últimas três décadas do século $X X$, chegando a duplicar o número de feirantes entre 
1990 e 2014. Os dados dos cadastros realizados pela Secretaria de Arrecadação da Prefeitura revelam que em 1990 estavam cadastrados 580 pessoas; após uma década, em 2000 o número evoluiu para 710, e o atual cadastro de 2014 registrou 1.210 feirantes (dados obtidos em 10/2014).

Acreditamos que esse aumento de trabalhadores nesta feira se explica devido o crescimento da população urbana e as mudanças dos setores econômicos que geram empregos. A partir de 1980 a população urbana de Cascavel/CE passou a ser superior a rural. Isso prova que Cascavel também incorporou o modelo de crescimento urbano acompanhado por pouca estrutura de setores de ocupação para sua população urbana.

Isso porque o processo de urbanização no Brasil foi acompanhado pela pobreza da população, que resultou em problemas estruturais e sociais no espaço urbano. Santos (2013) associa esse fato ao modelo de crescimento econômico escolhido pelo país, que repeliu agricultores do campo e desenvolveu uma indústria com pequena oferta de emprego. $\mathrm{O}$ terciário ${ }^{4}$ acabou recebendo 0 maior contingente de trabalhadores, associando formas modernas e primitivas de postos de trabalho. Tal situação configurou nas cidades as contradições do processo de modernização, por abrigar a maior quantidade de atividades de produção com diversas escalas de renda (SILVEIRA, 2007), incluindo os salários mais baixos.

Também se considera que as atividades dos setores hegemônicos exigem mão de obra qualificada e, ao contrário, nas grandes cidades brasileiras se formou um montante de pessoas não capacitadas, logo se destacam as diferenças salariais. Em Cascavel também se evidencia esse fato, pois a partir da análise do perfil sócio econômico dos feirantes entrevistados na feira de São Bento, mas de $50 \%$ possui apenas o Ensino Fundamental como podemos verificar no Gráfico 1.

Conforme os dados do Gráfico 1, do total de feirantes entrevistados, 107 deles possui apenas o Ensino Fundamental completo. Este nível apresenta valores acima do somatório dos outros níveis. Em segundo lugar, destacam-se os que já concluíram o Ensino Médio, enquanto o número de analfabeto está acima dos que possuem formação Superior.

\section{Gráfico 1 Nível de escolaridade dos feirantes da feira livre de São Bento}

\footnotetext{
${ }^{4}$ Segundo Vargas (2001, p. 52) '[...] o terciário pode ser definido como aquele que incorpora atividades que não produzem, nem modificam produtos ou mercadoria.
} 


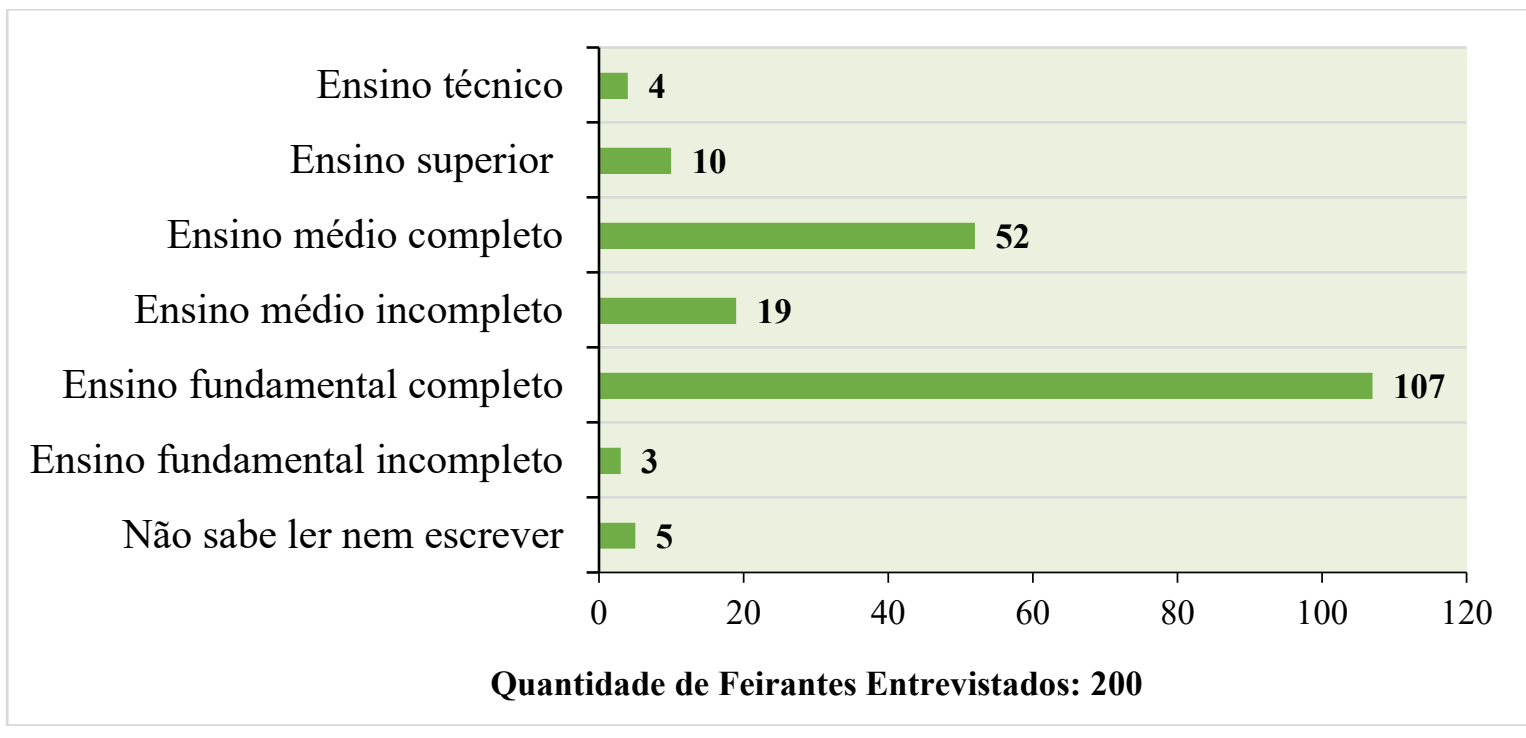

Fonte: Pesquisa de campo, 2016

Essa realidade social exposta no Gráfico 1 mostra a baixa qualificação dos trabalhadores da feira livre de São Bento e que também comprovam uma das variáveis apresentadas por Santos (2008) quanto ao perfil dos trabalhadores do circuito inferior ${ }^{5}$. $\mathrm{O}$ autor deixa claro que a baixa qualificação dos profissionais é um dos fatores que eleva o índice de trabalhadores em atividades nesse circuito. $O$ comércio é um ramo que mais recebe esse contingente, pois para iniciar um negócio é necessário muito mais a disponibilidade da força da mão de obra do que o grau de qualificação em si.

A partir dos anos de 1980, no Brasil houve uma redução do emprego assalariado formal, aumentou número de vagas assalariadas sem registros, assim como a precarização das condições de trabalho Montenegro (2006; 2011). Este panorama mostra a dificuldade de ingresso no mercado formal de trabalho e o aumento da pobreza. Esse cenário brasileiro foi bem visível em Cascavel/CE, pois no final da década de 1980 houve um aumento do corte de funcionários em algumas indústrias de médio e grande porte. Assim como no final da década de 1999, algumas indústrias fecharam sua portas, a exemplo da Pé de Ferro. Esses fatos remetem às discussões dos dois circuitos da economia urbana (SANTOS, 2008), quando a população chega à cidade e não é agregada nas atividades modernas. Como alternativa, muitos buscam meios de trabalhos nos setores que representam o circuito inferior.

E assim, as avenidas, ruas e calçadas são apropriadas e usadas por uma pluralidade de indivíduos entre feirantes, consumidores, políticos em suas propagandas eleitorais, pedintes, camelôs, engraxates, vendedores ambulantes, pregadores da palavra de Deus e turistas.

\footnotetext{
${ }^{5}$ Santos (2008) propôs uma teoria espacial para explicar a economia urbana dos países periféricos, através do circuito superior e inferior. $O$ circuito superior seria aquele constituído pelos bancos, pela indústria urbana moderna, pelos atacadistas, pelo comércio moderno (shopping centers, hipermercados ou supermercados), pelos serviços modernos. O circuito inferior seria formado, essencialmente, pelo trabalho familiar e pelos serviços e comércios não modernos de pequena dimensão.
} 
A organização da feira de São Bento começa na sexta-feira quando os montadores armam as barracas para que no sábado de madrugada os proprietários terminem de ornamentar o cenário, obra de arte de cada um (Figura 3, 4,5 e 6).Por volta das seis horas do sábado, o cenário está pronto para receber e apresentar aos visitantes as mercadorias. As barracas são na maioria de madeira, cobertas com lonas. Depois de meio dia de sábado os garis iniciam a limpeza das ruas ocupadas pelas barracas.

O espaço ocupado pela feira é organizado diferentemente, em função do tipo de mercadoria. Em cada setor os feirantes se apropriam de espaços fixos. Em cada rua, predomina um tipo de produto. A maior ou menor valorização do local para melhores vendas está relacionada com sua posição estratégica, ou seja, com os lugares de maior circulação de pessoas, a exemplo de esquinas e ruas próximas aos mercados e bancos.

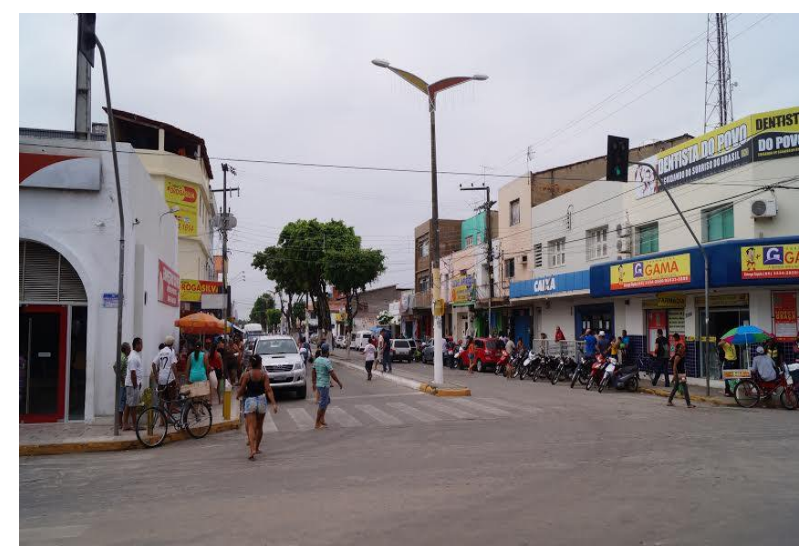

Figura 3 - Local da feira nos dias comuns.

Fonte: Kiko Barros, 2015

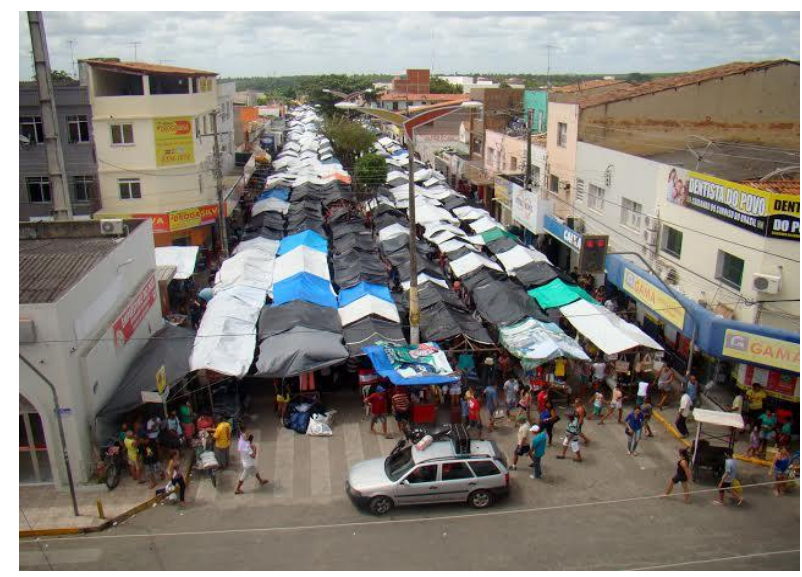

Figura 5 - Sábado pela manhã- horário da feira.

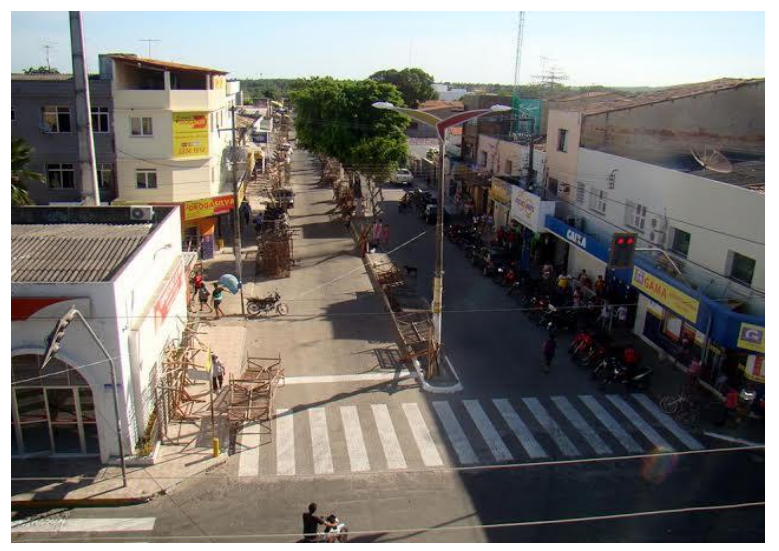

Figura 4 - Sexta-feira à tarde: Organização da feira Fonte: Kiko Barros, 2015

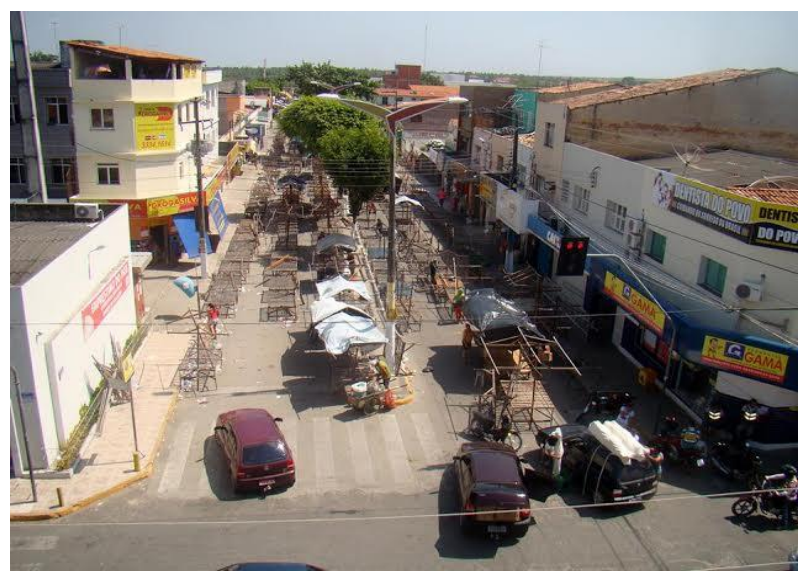

Figura 6 - Sábado à tarde: fim da feira.

A aquisição do local deveria ser intermediada somente pela prefeitura que organizou um cadastro para locar os feirantes. Porém, devido ao longo tempo de espera, mais de $50 \%$ dos feirantes compraram o lugar de outros que estão saindo 
do ramo de vendas nesse mercado (Gráfico 2). Na verdade, não se compra a barraca, mas o espaço para montá-la. O negócio é feito sem intermediação da prefeitura e sem documentos. Porém, uma vez adquirido o espaço o feirante passa a ter posse daquele local.

Outro aspecto que observamos quanto a localização na feira no centro da cidade foi a quantidade de serviços que estão ligados à dinâmica das vendas neste mercado periódico. As redes bancárias, mercados públicos, escritórios, clínicas médicas, pontos de taxi, mototáxi, posto de combustível e terminal rodoviário estão em torno da feira. A lógica de funcionamento da feira vincula-se às múltiplas demandas dos consumidores, já que eles aproveitam o mesmo dia para realizar diversas atividades. A consumidora Ana Paula, 32 anos, relatou que aproveita para ir ao centro de Cascavel no sábado, pois nesse mesmo dia faz compras na feira e na mesma oportunidade realiza exames clínicos.

Mesmo assim, a feira de Cascavel/CE se destaca pela sua dimensão espacial, pelas cores, barulhos, o calor natural e humano e a diversidade de produtos que, juntos conferem identidade à cidade, atraem consumidores e trabalhadores.

\subsection{A espacialização e comercialização das mercadorias na feira livre de São Bento.}

Para Salgueiro e Cachinho (2009) quando o capitalismo passou a ser sustentado pela indústria como o modo de produção se iniciou uma fase de consumo bem diferente dos outros períodos, pois, com a manufatura ocorreu uma ampliação da quantidade de mercadorias, sendo necessário vender. Com isso, o comércio retoma sua posição primaz pela demanda de novos produtos. Iniciou-se a expansão geográfica de mercado e os países de terceiro mundo passaram por um processo de modernização da universalização do consumo em massa.

Vieram as técnicas que criaram atividades especializadas com ampliação da Divisão social do trabalho. Além disso, também aumentou a margem para o aumento da produção e a "[...] propriedade privada dos produtos de consumo expandiu-se dos bens de produção" (VARGAS, 2001, p.21), o que abriu caminho para a troca estabelecida principalmente nas cidades.

O modo de produção de massa se caracteriza pelo avanço da tecnologia que impõe novas invenções e técnicas. Sistemas aperfeiçoados de comunicação, de fluxo de informação e racionalizações de técnicas de distribuição possibilitam maior velocidade de circulação de mercadoria (HARVEY, 2013). O referido autor considera ainda que a mercadoria passa a ser o centro da atenção e assume quase vida própria. O fácil acesso a diversificados produtos impulsiona o consumo massificado pela sociedade. A mercadoria encontrou as condições de reprodução nas formas diversificadas de comércio e na fluidez dos fluxos de informação. A sociedade contemporânea se veste de ilusões pela abundância de objeto com tempo de vida cada vez menor. A sociedade do "descarte" significa mais do que jogar fora bens produzidos. Significa também ser capaz de atirar fora valores, estilos de vida, relacionamentos estáveis, apego às coisas, edifício, lugares, pessoas e modos adquiridos de agir e ser (HARVEY, 2013, p.258).

Tudo isso se reflete na feira, no plano local, onde se verifica a maior quantidade de produtos. Elas também receberam uma gama muito maior de mercadoria. A partir de então, elas já não são somente lugares de troca de produtos 
e ultrapassam outros limites, também são lugares de consumo. Surgem elementos com ícones do novo que representa a cidade moderna. Independente da classe social que as frequentam, o desejo por novos objetos com estilo mais modernos tem influenciado no conteúdo das feiras livres.

Os novos elementos que chegam às feiras promovem novas relações de trocas e atrai novos consumidores. Na feira livre de São Bento já não se comercializam somente produtos de subsistência dos agricultores. Podemos observar pela Tabela 2 o quanto o perfil dos compradores mudou e veremos com mais detalhe como se distribuem os tipos de produtos que compõem cada categoria.

Tabela 2. Distribuição dos produtos por categoria

\begin{tabular}{|c|l|c|c|}
\hline Categoria & \multicolumn{1}{|c|}{ Produtos } & Quantidade & (\%) \\
\hline Manufaturados & $\begin{array}{l}\text { Confecção; Importados; } \\
\text { Calçados; Acessórios; } \\
\text { Ferramentas; Redes; } \\
\text { Brinquedos; Cosméticos; } \\
\text { Utilidade doméstica. }\end{array}$ & 925 & $82 \%$ \\
\hline Alimentos & $\begin{array}{l}\text { Frutas; legumes; Cereias; } \\
\text { horticultura; Lanche } \\
\text { Condimentos; Carnes }\end{array}$ & 155 & $13 \%$ \\
\hline $\begin{array}{c}\text { Artesanais } \\
\text { Rendas; bordados; } \\
\text { Objetos de cipó e palha; } \\
\text { flores; Objetos de barros. }\end{array}$ & 22 & $3 \%$ \\
\hline plantas & $\begin{array}{l}\text { Bovinos; Caprinos; Suínos; } \\
\text { Aves }\end{array}$ & 15 & $\mathbf{1 0 0 \%}$ \\
\hline
\end{tabular}

Fonte: Cadastro dos feirantes realizado pela Prefeitura Municipal de Cascavel/CE, 2014.

Conforme os dados apresentados da Tabela 2 os produtos manufaturados são os mais ofertados com $82 \%$ total de feirantes cadastrados. Esses valores são representados pelos produtos eletrônicos, brinquedos, utensílios domésticos; CDs piratas, vestuários e alimentos industrializados (Figura 7) Já, os produtos artesanais em couro, barro, palha, madeira, bordados, labirintos e rendas, formam um grupo bem menor (Figura 9). Os produtos alimentícios (Figura 8) que outrora predominava na feira de São Bento, hoje ocupam a segunda posição, com 13\%. 


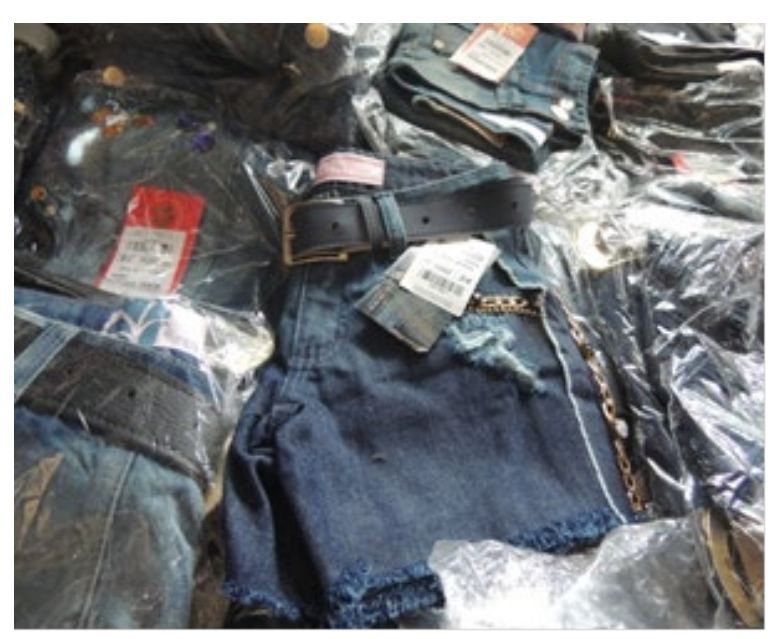

Figura 7- . Vestuários predominante.

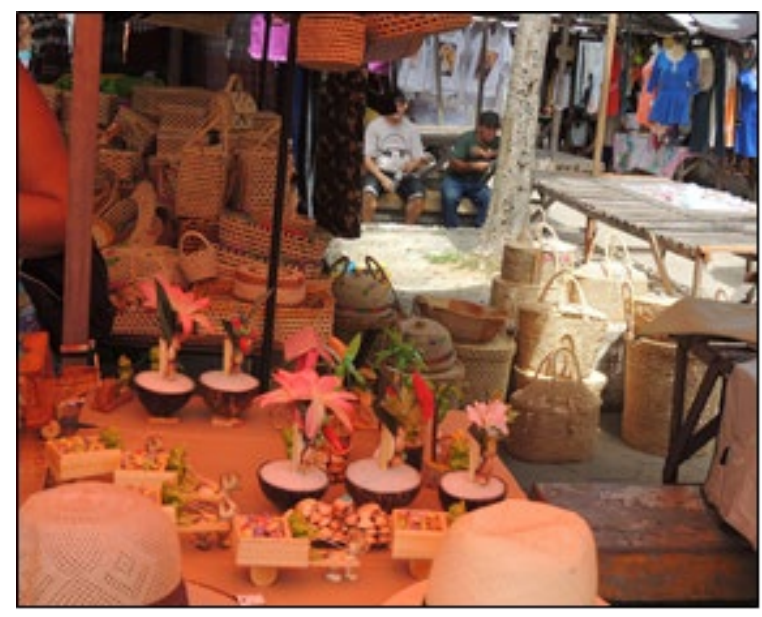

Figura 9 - Artesanato local.

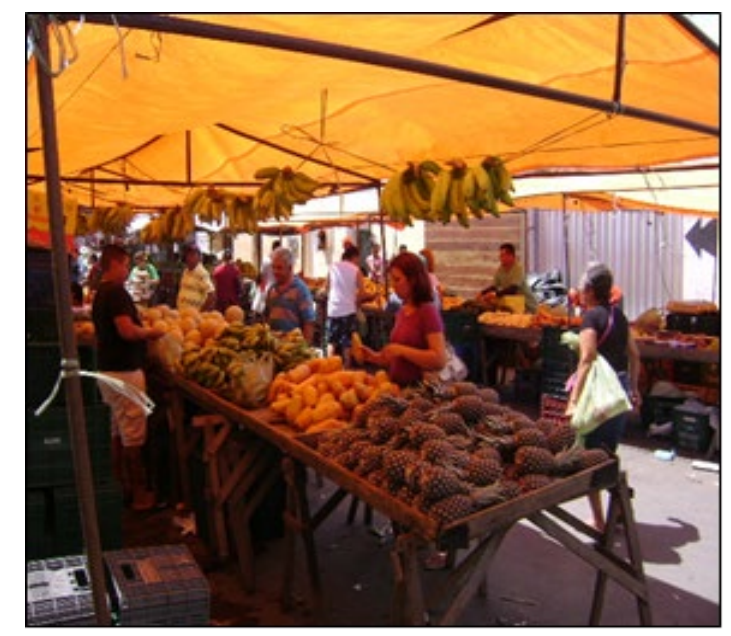

Figura 8 - Setor de alimentos.

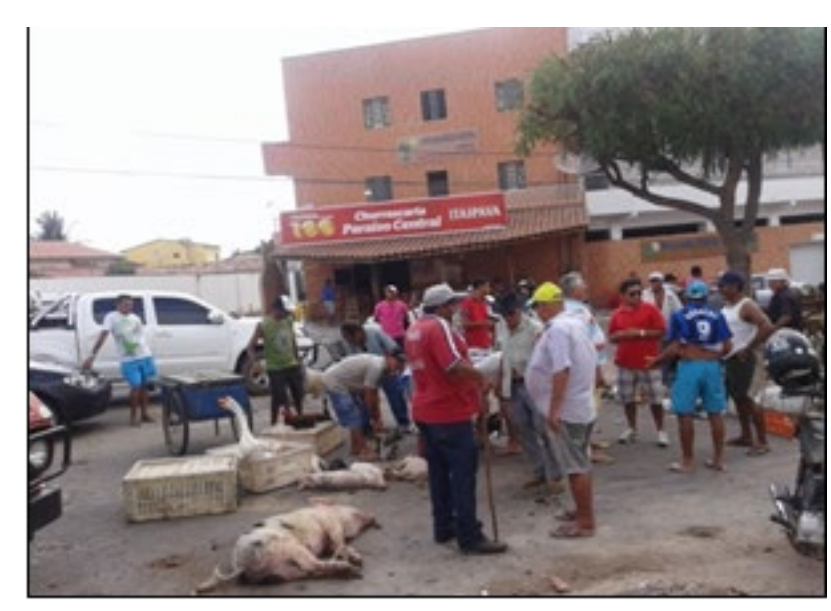

Figura 10- Venda de animais.

Percebemos, que a feira de São Bento possui características semelhantes a outras feiras do Nordeste, como também apresenta peculiaridade, o que a torna mais atrativa. Enfim, a feira se expandiu e transformando-se até os dias atuais, revela as mudanças nas técnicas através dos objetos que são expostos à venda, e hábitos de consumo de sua população.

\section{Considerações finais.}

A sistematização dos dados da pesquisa constatou que as feiras livres permanecem vivas porque possuem raízes profundas regadas pelas amplas relações socioeconômicas. Ao mesmo tempo elas se ajustam as atuais realidades 
e convivem às vezes harmonicamente ou não, mas também atendem os novos modos de consumir da sociedade.

A feira de São Bento é um exemplo das que criaram vínculos com a cidade. Ela sofreu profundas mudanças de conteúdos e na forma como resposta das ações dos agentes sociais, ou seja, atualmente se remodela com elementos que emergiram da modernidade. Entretanto, ainda apresenta detalhes do passado, quando visualizamos em sua paisagem: a organização, as mercadorias e as relações de compra e venda entre vendedor e consumidor. Neste sentido, a ideia sobre o espaço de Santos (1978) explica esse processo, pois os novos objetos que se instalam no espaço geográfico influenciam os já existentes com novas funções. O que Santos (1978) chamou de ruptura, ou seja, a mudança do conteúdo histórico através do seu percurso.

Quanto ao conteúdo, tendo como referência a categorização dos produtos na feira de São Bento, compreendemos a mudança do consumo nestes espaços. A categoria dos manufaturados apresenta maior variedade dos produtos o que revela, que a feira de São Bento atende aos novos padrões de consumo da população. Ela funciona como polo de distribuição do comércio a varejo dos produtos da produção dos produtores de calçados, vestuários e outros artigos. A venda de alimentos sempre existiu, entretanto, devido as precárias condições de higiene, os consumidores procuram outras formas comerciais. Os produtos artesanais são os que apresentam menor demanda, embora que no pretérito, predominavam nessa feira. O comércio de animais revela o mais tradicional das feiras nordestinas e representa uma resistência em São Bento.

Enfim, a feira livre de São Bento se manifesta, atualmente, vivas no espaço e mesmo com suas particularidades próprias, responde às mudanças impostas pelo sistema político e socioeconômico, em cada período na história. As mudanças do perfil das feiras livres estão relacionadas à reorganização da economia e da sociedade, que vem ocasionando diversificação e aprofundamento do consumo.

\section{Agradecimentos}

Agradeço à minha orientadora, Prof ${ }^{a}$. Dra . Denise Cristina Bomtempo, pela leitura do texto e pelas contribuições do mesmo.

\section{Referências}

ARAÚJO, G. Continuidade e descontinuidade no contexto da globalização: um estudo de feiras em Portugal e no Brasil (1986-2007). 2011. 700f. Tese (Doutorado) - Programa em Pós-Graduação em História Social, Universidade Federal da Bahia, 2011.

BESSA, E. R. Cascavel: 300 anos. 2. ed. Fortaleza: Universidade de Fortaleza, 2001.

BRAUDEL, F. Civilização material, economia e capitalismo: séculos XVIXVIII Vol. II - O jogo das trocas. 2. ed. São Paulo: Martins Fontes, 1998. 
BROMLEY, R.J. Os mercados periódicos dos países em desenvolvimento: uma revisão crítica. Revista Brasileira de Geografia. Rio de Janeiro, IBGE, p. 646-57, jul./set. 1980.

CORREAA, R. L. O espaço urbano. São Paulo: Ática, 1995.DIAS, Chistina Leila. Redes: emergência e organização. In:

COSTA. M. R. Dinâmica espacial da feira livre de São Bento em Cascavel/ce. 2016. 216f. Dissertação de Mestrado. Universidade Estadual do Ceará, Fortaleza, 2016.

GODOY, W. I. As feiras-livres de Pelotas, RS: estudo sobre a dimensão sócioeconômica de um sistema local de comercialização.2005. 284f. Tese (Doutorado)- Universidade Federal de Pelotas, Pelotas (RS), 2005.

HARVEY, D. A condição pós-moderna. São Paulo: Edições Loyola, 1993.

JESUS, M. O lugar da feira-livre na cidade capitalista. Revista de Geografia. Rio de Janeiro, v. 54, n. 1, p. 95-121, 1992.

MEDEIROS, J. F. As feiras livres em Belém (PA): Dimensão Geográfica e Existência Cotidiana. Dissertação (Mestrado). 118f. Programa de Pós-Graduação em Geografia, Universidade Federal do Pará, Belém, 2010.

MONTENEGRO, M. R. Globalização, trabalho e pobreza no Brasil metropolitano:O circuito inferior da economia urbana em São Paulo, Brasília, Fortaleza e Belém. 2011. 291f. Tese (Doutorado) - Universidade de São Paulo, São Paulo, 2011.

ORTIGOZA, S. A. Paisagem do consumo: São Paulo, Lisboa, Dubai e Seul. São Paulo: Cultura Acadêmica, 2010.

PINTAUDI, S. M. A cidade e as formas do comércio. In: CARLOS, Ana Fani Alessandri (Org.). Novos caminhos da Geografia. São Paulo: Contexto, p. 143-159, 2002

SALGUEIRO, T. B; CACHINHO, H. As relações cidade-comércio dinâmicas de evolução e modelos interpretativos. In: CARRERAS, Carles; PACHECO, Susana Mara Miranda (Orgs.). Cidade e Comércio: a rua comercial na perspectiva internacional. Rio de Janeiro: Armazém das Letras, p. 9-39, 2009.

SANTOS, M. A natureza do espaço: técnica e tempo, razão e emoção. 2. ed. São Paulo: EDUSP, 2006.

. O espaço dividido: os dois circuitos da economia urbana dos países subdesenvolvidos. 2. ed. São Paulo: EDUSP, 2008.

SHEPARD F. Camponeses: sua participação no Brasil. Rio de Janeiro, 2009.

SILVEIRA, M. L. Crises e paradoxos da cidade contemporânea: os circuitos da economia urbana. In: PEREIRA, Elson Manoel Pereira; DIAS, Leila Cristina Dias (Orgs.). As cidades e a urbanização no Brasil: passado, presente e futuro. 1. ed. Florianópolis: Insular, v. 1, p. 62-82, 2011.

VARGAS, H. C. Espaço do terciário: o lugar, a arquitetura e a imagem do comércio. São Paulo: Editora SENAC, 2001. 